\title{
ST-Segment Elevation Myocardial Infaction Alert During the Night Shift, A Misfortune for the Patient or an Overstatement?
}

\author{
Waqas Ullaha, c, Muhammad Arslan Cheema ${ }^{\mathrm{a}}$, Hafez Mohammad Ammar Abdullah ${ }^{\mathrm{b}}$, \\ Sohaib Roomi ${ }^{\mathrm{a}}$, Rehan Saeed ${ }^{\mathrm{a}}$, Asoka Balaratna ${ }^{\mathrm{a}}$
}

\begin{abstract}
Background: Conflicting data exist regarding the outcomes of primary percutaneous coronary intervention (PCI) for ST-segment elevation myocardial infarction (STEMI) based on intervention timings. It is believed that short staffing at night hours may lead to a lapse in the delivery of effective, efficient and timely medical intervention.
\end{abstract}

Methods: A retrospective single-center study was performed, and a total of 436 patients were randomized into two groups. Group A had 279 patients who had the heart catheterization done during the daytime (between 6 am and $6 \mathrm{pm}$ ), while group B had 157 patients who had the same intervention performed at night (between $6 \mathrm{pm}$ and $6 \mathrm{am}$ ).

Results: Door to balloon (DTB) time during the day was about 16 min shorter than the DTB time at night $(81.29 \pm 3.26$ vs. $97.30 \pm 8.54)$ with no statistical difference $(\mathrm{P}=0.051)$. The mean troponin rise during the day was $1.94 \pm 10.60$ SEM (95\% confidence interval (CI): -22.70 to $18.90)$ higher than night troponin levels $(71.75 \pm 7.18$ vs. $69.80 \pm 7.18)$, but $\mathrm{P}$ value was 0.85 . The left ventricular ejection fraction (LVEF) fall for daytime was $0.93 \%$ vs. $0.90 \%$ for night time patients $(\mathrm{P}=0.94)$.

Conclusion: There is no significant difference in the mean DTB time, the rise in troponin, fall in LVEF, readmission rates, or mortality, and hence no negative effects on patient outcomes based on the patient's time of presentation between the two groups.

Keywords: STEMI alert; Coronary intervention; Acute coronary syndrome

\section{Introduction}

Cardiovascular diseases are responsible for about one-third

Manuscript submitted April 5, 2019, accepted April 29, 2019

aAbington - Jefferson Health, Abington, PA, USA

bUniversity of south Dakota Sanford school of medicine, Sioux Falls, SD, USA

${ }^{\mathrm{c} C}$ Corresponding Author: Waqas Ullah, Abington - Jefferson Health, 1200 Old

York Road, Abington, PA 19001, USA. Email: waqasullah.dr@gmail.com

doi: https://doi.org/10.14740/cr862 of all deaths in the United States. Acute coronary syndromes (ACS) constitute one in every five deaths, with the ST-segment elevation myocardial infarction (STEMI) representing 30-45\% of all ACS [1]. This highlights the importance of prompt management of STEMI in order to preserve cardiac contractility and decrease mortality $[2,3]$. The estimated increase in 1-year mortality is about $7.5 \%$ for every 30 -min delay in STEMI reperfusion therapy [4]. Many trials showed that revascularization with percutaneous coronary intervention (PCI) is superior to thrombolytic therapy for acute STEMI but time is of an essence here $[5,6]$.

The American College of Cardiology (ACC) has provided recommendations for the management of STEMI that PCI should be performed within $90 \mathrm{~min}$ of STEMI presentation. Despite these recommendations, less than half of patients receive PCI within this time frame [7, 8]. This led to the introduction of various strategies such as use of prehospital electrocardiography (ECG), centralized alert system to activate the catheterization lab and availability of 24/7 emergency response team, all to improve the door to balloon (DTB) time in patients receiving primary PCI $[9,10]$. Additionally, ACC gave recommendations that advanced cardiac life support providers should be able to perform and evaluate the 12-lead ECG routinely on all patients with suspected STEMI [7].

Despite these measures, there has been a significant delay in DTB timing for STEMI patients risking millions of lives. This could be attributed to a confounding variable in meeting the above mentioned ACC guidelines that is DTB highly variable for the time of day or day of the week for STEMI patients. In this study, we sought to determine the DTB time difference for patients presenting during daytime with respect to night time. We also aimed to identify the sources of delay by looking into the different fragment of standard ACC model, that is, prehospital ECG coupled with a centralized emergency department notification, "Cath Alert" in the hospital system, staff availability, delay in the emergency room (ER) and transmission of ECG, while the patient is en route to a receiving station in the ER.

\section{Materials and Methods}

This study was conducted at Abington Hospital - Jefferson Health, a receiving hospital serving a large suburban and rural 
community. All acute STEMI patients who had primary PCI done with or without stent placement were deemed eligible for inclusion into the study. The hospital has a 24-h on-call coronary catheterization team consisting of an interventional cardiologist, specialized nurses, a cardiology fellow, ancillary staff and transport personnel. The catheterization laboratory is located on the first floor, while the emergency department is on the ground floor of the same building. This study did not involve direct patient interaction or animal subjects and was approved by the hospital ethics committee and Institutional Review Board.

\section{Study population}

We performed a retrospective single centered study including patients from 2015 to 2018. A total of 436 acute STEMI patients presented either directly, transferred from Lansdale Hospital to the emergency department or directly to the catheterization lab were included in the study. STEMI was defined as $\geq 1 \mathrm{~mm}$ in at least two contiguous ECG leads or new onset of complete left bundle-branch block, while treatment with primary PCI was angioplasty with or without stent deployment. Patients with prior fibrinolytic treatment or presenting on weekends were excluded from the study. DTB time was calculated by the time from the first ECG showing STEMI to first inflation of balloon PCI.

\section{Data collection and analysis}

For all the included patients, the demographic (age and gender) and clinical information was collected by retrospective chart review. The clinical data included baseline characteristics and risk factors for STEMI such as hypertension, diabetes mellitus (DM), smoking, hypercholesterolemia, prior history of coronary artery disease (CAD), PCI or bypass surgery. All patients were randomized into two groups based on time of presentation. Group A included patients who had PCI done from 6 am to $6 \mathrm{pm}$ and group $\mathrm{B}$ included patients who had PCI done from $6 \mathrm{pm}$ to $6 \mathrm{am}$. Serum troponin levels were determined before and after PCI for each of the two groups. Similarly, postprocedure left ventricular ejection fraction (LVEF) on transthoracic echocardiography was compared with preprocedure LVEF by looking at the medical record. For each group, the femoral and radial approaches of PCI were also taken into consideration. In-hospital mortality and readmission rates for discharged patients were also calculated for each group.

This study was approved by ethics committee and by the Institutional Review Board of our center. Continuous variables were compared using the independent $t$-test and nominal variables by using the $\chi^{2}$ and Fisher's exact test using SPSS version 2.0. Values of $\mathrm{P} \leq 0.05$ were considered significant.

\section{Results}

The baseline characteristics in the two groups are summarized
Table 1. Baseline Patient Characteristics

\begin{tabular}{lll}
\hline & \multicolumn{2}{c}{ Time of the day } \\
\cline { 2 - 3 } & Night & Day \\
\hline Mean age (years) & 64.56 & 66.39 \\
Sex (males) & $68.79 \%(\mathrm{n}=108 / 157)$ & $57.70 \%(\mathrm{n}=161 / 279)$ \\
CHF & $12.10 \%(\mathrm{n}=19 / 157)$ & $6.45 \%(\mathrm{n}=18 / 279)$ \\
Known CAD & $25.47 \%(\mathrm{n}=40 / 157)$ & $17.20 \%(\mathrm{n}=48 / 279)$ \\
Smokers & $61.14 \%(\mathrm{n}=96 / 157)$ & $44.44 \%(\mathrm{n}=124 / 279)$ \\
HLD & $27.38 \%(\mathrm{n}=43 / 157)$ & $20.7 \%(\mathrm{n}=58 / 279)$ \\
PVD & $1.27 \%(\mathrm{n}=2 / 157)$ & $3.58 \%(\mathrm{n}=10 / 279)$ \\
DM & $22.92 \%(\mathrm{n}=36 / 157)$ & $21.50 \%(\mathrm{n}=60 / 279)$ \\
HTN & $58.59 \%(\mathrm{n}=92 / 157)$ & $47.31 \%(\mathrm{n}=132 / 279)$ \\
\hline
\end{tabular}

CHF: congestive heart failure; CAD: coronary artery disease; HLD: hyperlipidemia; PVD: peripheral vascular disease; DM: diabetes mellitus; HTN: hypertension.

in Table 1 and Figure 1. The mean age of all of the patients was 65.68 years (standard deviation (SD): 14.09). The mean age of the patients presenting at night was 64.56 years (SD: 13.88) against 66.39 years (SD: 14.21) in patients who presented during the day. Patients who presented during the day were $57.70 \%(n=161 / 279)$ males, versus the patients presenting at night, amongst whom $68.79 \%(n=108 / 157)$ were males.

Smoking was very common in our patient population, and $61.14 \%(n=96 / 157)$ of the patients presenting at night were current or prior smokers. This rate was $44.44 \%(n=124 / 279)$ in patients presenting during the day. Hypertension was the most common co-morbidity, with $58.59 \%(n=92 / 157)$ of the patients presenting during the night, and $47.31 \%(n=132 / 279)$ patients presenting during the day. Hyperlipidemia and diabetes were also common. Hyperlipidemia was present in $27.38 \%$ $(\mathrm{n}=43 / 157)$ of the patients in the night group, and in $20.7 \%$ $(\mathrm{n}=58 / 279)$ during the day group. Diabetes was present in $22.92 \%(\mathrm{n}=36 / 157)$ patients during the night, and in $21.50 \%$ $(n=60 / 279)$ of the patients presenting during the day. Besides this, peripheral vascular disease was present in $1.27 \%(\mathrm{n}=$ $2 / 157)$ patients presenting during the day and in $3.58 \%(\mathrm{n}=$ 10/279) patients presenting during the night. Pre-existing heart failure was present in $12.10 \%(n=19 / 157)$ patients in the night group and in $6.45 \%(\mathrm{n}=18 / 279)$ patients in the day group. Of the patients, $25.47 \%(\mathrm{n}=40 / 157)$ in the night group also had known CAD and $17.20 \%(n=48 / 279)$ in the day group had known CAD.

All the values are means with standard errors, unless mentioned otherwise. The mean DTB time during the day was $81.29 \pm 3.26$, which was shoter than the mean DTB time at night $(97.30 \pm 8.54)$. There was the homogeneity of variances, as assessed by Levene's test for equality of variances with $\mathrm{P}$ value of $0.118(\mathrm{P}>0.05)$. The mean DTB time during the day was $-16.05 \pm 8.20$ (95\% confidence interval (CI): -39.17 to 2.21) as compared to the mean DTB time during the night. However, the P-value was $0.051(\mathrm{P}>0.05)$, signifying no statistical significance between the two groups in the DTB time. Four patients presenting during the night did not have a calcu- 


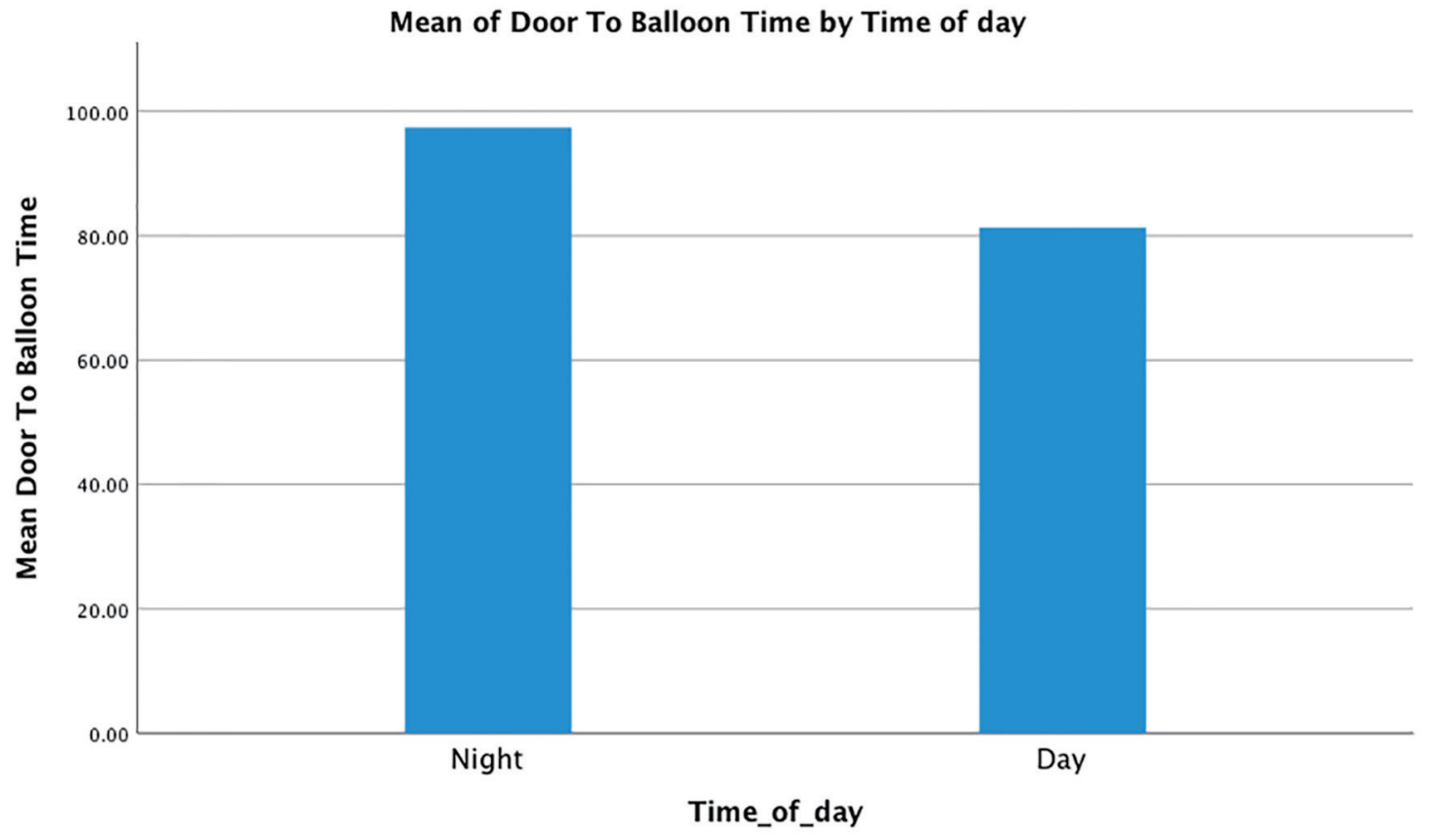

Figure 1. Baseline patient characteristics.

lated DTB time as PCI was not performed. This is depicted in Figure 2.

Interestingly, the mean troponin rise during the day was $71.75 \pm 7.18$, which was higher than the mean troponin rise at night $(69.80 \pm 7.18)$. There was the homogeneity of variances, as assessed by Levene's test for equality of variances with $\mathrm{P}$ value of $0.50(\mathrm{P}>0.05)$. The mean troponin rise during the day was $1.94 \pm 10.60$ SEM (95\% CI: -22.70 to 18.90$)$ higher than the mean troponin rise during the night. However, the Pvalue was $0.85(P>0.05)$, signifying no statistical significance between the two groups in the troponin rise. This is shown in Figure 3.

Very few patients had a decrease in LVEF, on average a mean fall in LVEF of just $0.93 \%$ in patients presenting during

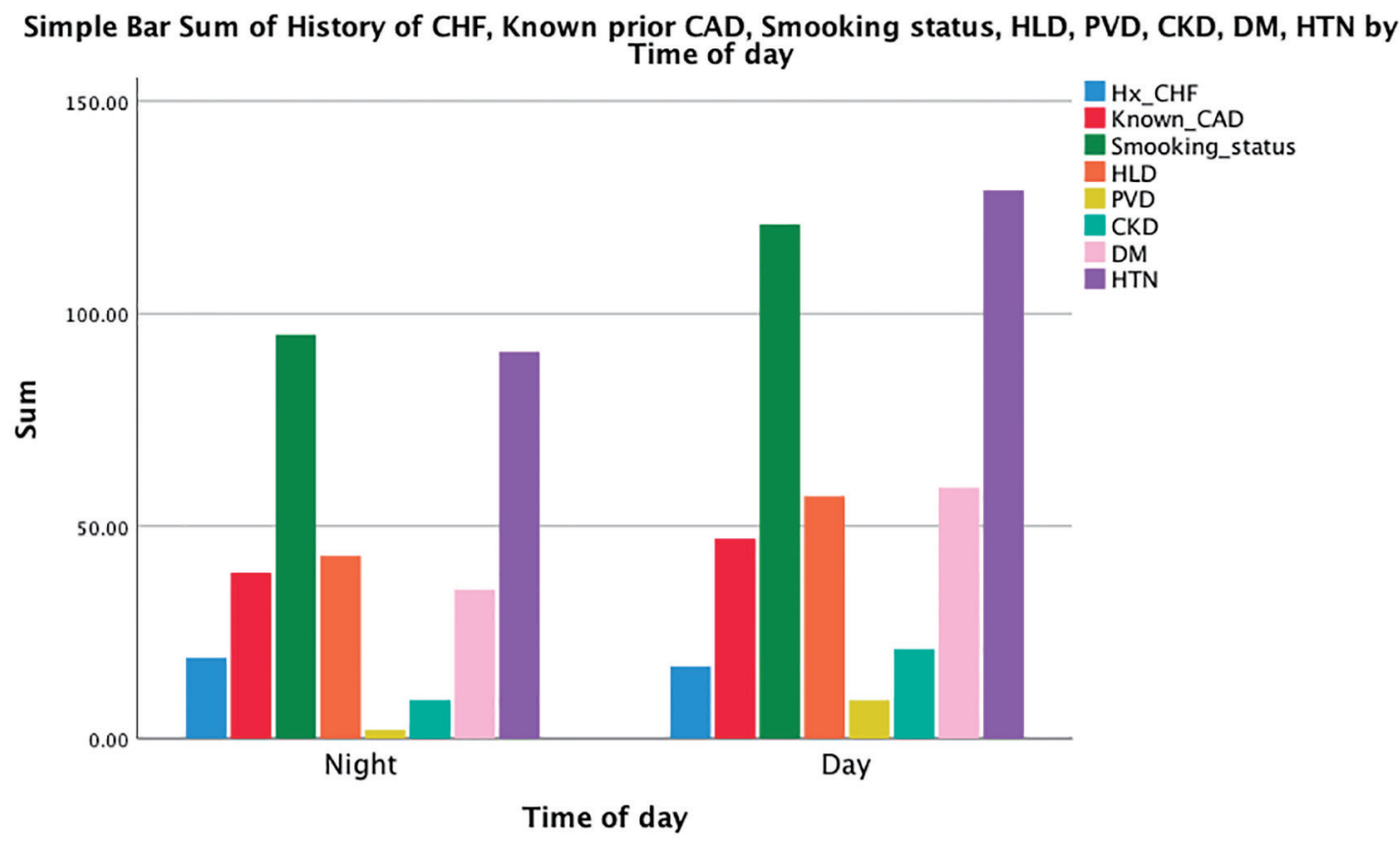

Figure 2. The mean door to balloon times in both groups. 


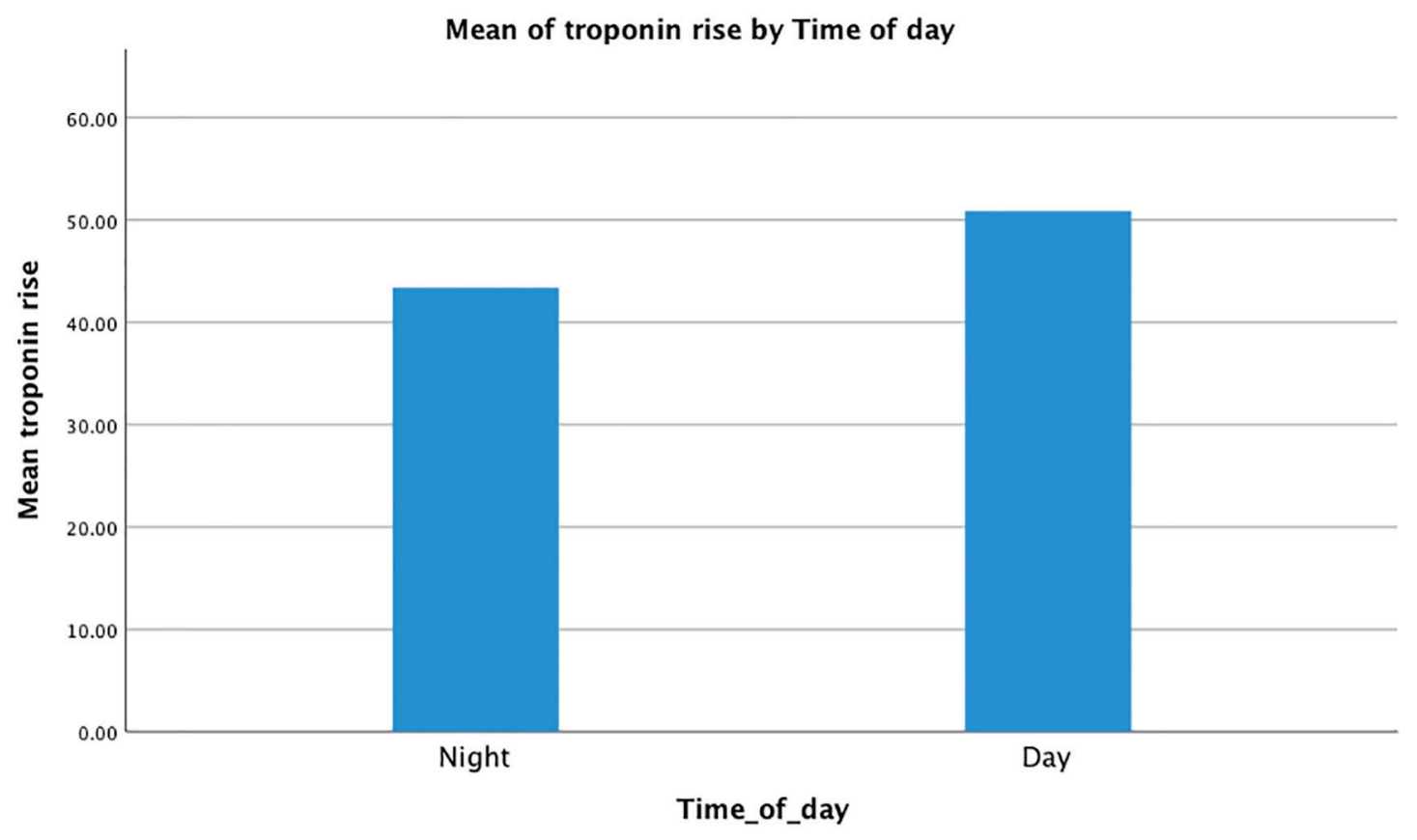

Figure 3. Mean troponin I rise in both groups.

the day vs. $0.90 \%$ during the night, with a P-value of 0.94 that was also not statistically significant. This is depicted in Figure 4.

A total of 14 patients were readmitted in 30 days, of which nine had initially presented during the day and five during the night. Two readmissions were due to a fall, three due to dyspnea and nine due to chest pain. Out of the chest pain group, one

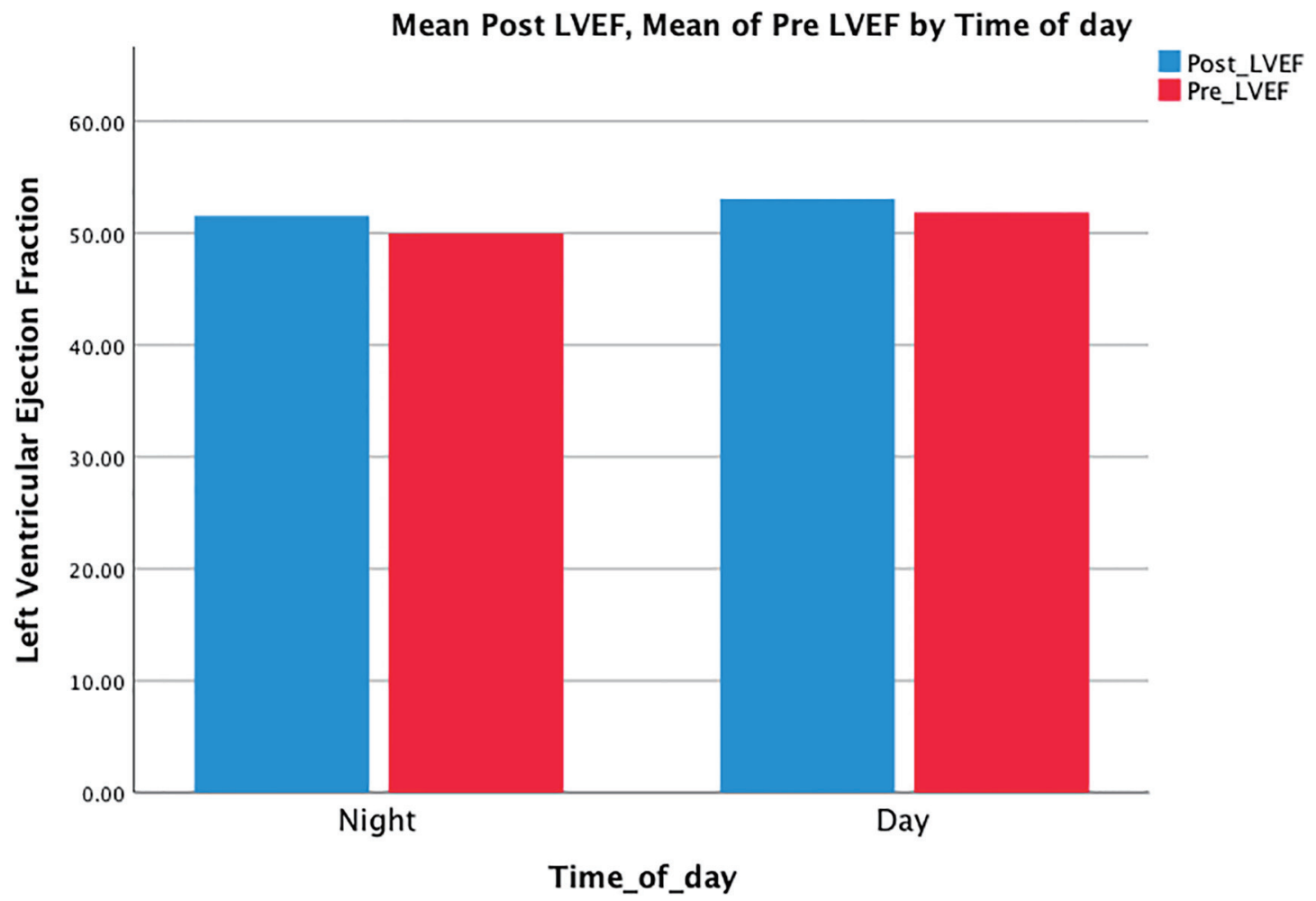

Figure 4. Mean differences in the left ventricular ejection fraction in both groups. 
Table 2. Outcomes and Complications in Both Groups

\begin{tabular}{lll}
\hline & \multicolumn{2}{c}{ Time of the day } \\
\cline { 2 - 3 } & Night & Day \\
\hline CVA & $1.91 \%(\mathrm{n}=3 / 157)$ & $1.07 \%(\mathrm{n}=3 / 279)$ \\
New HF & $7.64 \%(\mathrm{n}=12 / 157)$ & $5.37 \%(\mathrm{n}=15 / 279)$ \\
Cardiogenic shock & $7.64 \%(\mathrm{n}=12 / 157)$ & $7.88 \%(\mathrm{n}=22 / 279)$ \\
Mortality & $1.27 \%(\mathrm{n}=2 / 157)$ & $0.3 \%(\mathrm{n}=1 / 279)$ \\
30-day readmission & $3.18 \%(\mathrm{n}=5 / 157)$ & $3.22 \%(\mathrm{n}=9 / 279)$ \\
\hline
\end{tabular}

CVA: cerebrovascular accident; HF: heart failure.

patient had stent thrombosis and one patient had pericarditis. Three patients died during the study, two of whom presented during the night and one during the day. The mortality and readmission data were too insignificant to analyze. This is depicted in Table 2.

\section{Discussion}

This study unmasked the importance of intervention time in acute STEMI patients undergoing primary PCI. Although there was no statistically significant difference in the intervention time, ejection fraction or troponin peaks for the day vs. night time groups, there was about 20 min delay in the DTB timing for night group. The broad CI here signifies that larger population studies and multicentered approach might make the difference significant by increasing the power of the study. There was no increase in the in-hospital or long-term mortality for these groups which signifies the fact that the ACG DTB guidelines have been effective and institution was compliant to the recommendations. Moreover, in our study, the angiographic, clinical outcomes in terms of hospital stay, complications and procedural success are different between the two groups.

It is believed that night time intervention is not an independent predictor of in-hospital mortality for STEMI patients as the burden of PCI procedure can be high at night [11]. Some authors believe that there is a peak in platelet aggregation and increase in the viscosity of blood at night bringing variation in the coronary blood flow at night [12]. However, in our study, the trend was opposite and more frequent PCI procedures were observed during the day time. This can be attributed to the postulation that most older and female patients perhaps wait for the daytime for hospital admission especially in cases of subtle or atypical symptoms.

Most studies have suggested that the postprocedural success is lower for PCI done at night and there have been reports of higher in-hospital mortality in these groups [12-14]. Magid et al in their study established that the DTB time and mortality were significantly higher for off times than for regular hours (116.1 vs. $94.8 \mathrm{~min}, \mathrm{P}<0.001$ and odds ratio (OR): 1.07; 95\% CI: $1.01-1.14 ; \mathrm{P}=0.02$, respectively) [11]. Similar findings were reported by Glaser et al, that the in-hospital mortality was significantly higher in off hours PCI procedures (OR: 2.66, 95\% CI: 1.39 - 4.56; $\mathrm{P}=0.002$ ) [15]. Our study, however, excluded the population who had PCI on the weekends, but the night time PCI procedure or STEMI-related mortality was not different from the daytime mortality.

"MITRA" trial also showed that the DTB time was significantly higher in patients presenting at night times compared to those presenting during peak hours $[16,17]$. There was a 9 min in-hospital delay in MITRA trial for the night time vs. day PCI (85 min day, 94 min night, $P=0.037$ ) which was ironically statistically significant in contrast to our study where the average difference is higher but there is no statistical significance [16]. Interestingly, the prehospital delay for night time PCI was $60 \mathrm{~min}$ shorter than daytime with a $\mathrm{P}$ value of 0.005 for those patients [16]. This could be due to the fact that transportation is easier at night than day rush hours. These findings were substantiated by "CADILLAC" trial where DTB time for night was 129 vs. 108 min for daytime $(\mathrm{P}<0.0001)$ [17]. Ortolani et al found that patients treated during off hours had a reperfusion time $20 \mathrm{~min}$ higher than (199 vs. $179 \mathrm{~min}, \mathrm{P}=0.052$ ) regular hours [18]. Despite the reported delays due to time variations, there was no statistical difference in the clinical course and outcomes of the two groups [18]. The findings of our study are consistent with these trials but our study is different from these trials as we excluded patients presenting on weekends to reduce the subjective bias. The ancillary staff, transportation and cardiologists on weekends are different on weekends which can change the results.

The peak troponin and change in ejection fraction were used as a marker of damage to the myocardium in our study. There was no statistical difference in these findings for the two groups despite the DTB time delay of about 20 min on average in the whole population. Furthermore to reduce the confounding factors both groups in our study were matched on the basis of their comorbidities, average age and gender. In MITRA trial, the in-hospital mortality was about $7.9 \%$, while CADILLAC trail calculated 30 days mortality which was $2 \%$; in our study this number was just $0.68 \%(3 / 436)$ in the whole patient population $[16,17]$. It was $1.27 \%(\mathrm{n}=2 / 157)$ in the patients presenting at night and $0.3 \%(\mathrm{n}=1 / 279)$ in patients presenting during the day. This figure was too small to analyze. Our study is different from these trials as we did not exclude patients with cardiogenic shock and all risk factors for STEMI were taken into account.

Our results highlight the importance of the time sensitive approach to STEMI. All attempts to shorten the DTB time should be taken. Some suggestions are to unite small centers and have a larger high volume angioplasty center with 24/7 availability of the staff and expert interventional cardiologists. In-patient hospital delay can be avoided by bypassing the ER, centralized system where ECG can be transferred directly to the on-call cardiologist and cardiac cath lab should be kept informed by the EMS once a patient is transported. Patient transportation can be expedited by the use of helicopter and the first responders to STEMI should be trained to identify ischemic changes on ECG. Our findings are consistent with previous studies, where STEMI patients treated at large centers have a lower mortality than low-volume centers [19]. The ACC suggests that primary PCI should be used only if performed by cardiologist with experience of $>75$ elective PCIs/year and at least 11 primary PCIs/year and by institutions doing $>400$ elective and $>36$ primary PCIs/year [20]. This may be the reason the outcomes are better at our institution as we perform 
$>600$ PCIs/year and have expert interventional cardiologists.

There are certain limitations of this study: the study was single center and the population included was small. Moreover, it was a retrospective study, so randomization could not be done. But efforts were made to make the two groups as comparable as possible.

\section{Conclusion}

This study shows that patients treated at night with respect to daytimes by primary PCI have different DTB times, but this difference may not be as clinically relevant as initially thought. The presentation, clinical outcomes, hospital stays, complication rates and 30 days mortality may not be statistically different, provided the PCI is performed at a high-volume angioplasty center and the staff is experienced.

\section{Summary}

What is already known about this subject? 1) There is a significant difference between DTB time in patients presenting at night than day. 2) This increases the mortality of the patients and cardiac outcomes.

What are the new findings? 1) There is no difference in the DTB time if we exclude weekends and remove confounding factors. 2) If we follow the suggested recommendations, then mortality can be decreased significantly.

How might it impact on clinical practice in the foreseeable future? If the proposed recommendations are followed, then there will be a significant decrease in STEMI-associated mortality. There will be decrease in the devastating outcomes of myocardial infarction by lowering the DTB time for STEMI intervention.

\section{Acknowledgments}

We want to thank Dr. Margot Boigon for her support and help in providing the research opportunity. The abstract of this article was presented as a poster at the American Federation for Medical Research.

\section{Financial Disclosure}

None.

\section{Conflict of Interest}

None.

\section{Informed Consent}

Not applicable.

\section{Author Contributions}

Waqas Ullah wrote the manuscript and helped in analysis. Muhammad Arslan Cheema coordinated the data collection. Ammar Abdullah did the statistical analysis. Sohaib Roomi helped in reference arrangement and data mining. Rehan Saeed helped in literature review and data collection. Asoka Balaratna did the critical review and supervision.

\section{References}

1. Thom T, Haase N, Rosamond W, Howard VJ, Rumsfeld J, Manolio T, Zheng ZJ, et al. Heart disease and stroke statistics - 2006 update: a report from the American Heart Association Statistics Committee and Stroke Statistics Subcommittee. Circulation. 2006;113(6):e85-151.

2. Boersma E, Maas AC, Deckers JW, Simoons ML. Early thrombolytic treatment in acute myocardial infarction: reappraisal of the golden hour. Lancet. 1996;348(9030):771775 .

3. Cannon CP, Gibson CM, Lambrew CT, Shoultz DA, Levy D, French WJ, Gore JM, et al. Relationship of symptomonset-to-balloon time and door-to-balloon time with mortality in patients undergoing angioplasty for acute myocardial infarction. JAMA. 2000;283(22):2941-2947.

4. De Luca G, Suryapranata H, Ottervanger JP, Antman EM. Time delay to treatment and mortality in primary angioplasty for acute myocardial infarction: every minute of delay counts. Circulation. 2004;109(10):1223-1225.

5. Grines CL, Browne KF, Marco J, Rothbaum D, Stone GW, O'Keefe J, Overlie P, et al. A comparison of immediate angioplasty with thrombolytic therapy for acute myocardial infarction. The Primary Angioplasty in Myocardial Infarction Study Group. N Engl J Med. 1993;328(10):673-679.

6. Zijlstra F, Hoorntje JC, de Boer MJ, Reiffers S, Miedema $\mathrm{K}$, Ottervanger JP, van 't Hof AW, et al. Long-term benefit of primary angioplasty as compared with thrombolytic therapy for acute myocardial infarction. N Engl J Med. 1999;341(19):1413-1419.

7. Antman EM, Anbe DT, Armstrong PW, Bates ER, Green LA, Hand M, Hochman JS, et al. ACC/AHA guidelines for the management of patients with ST-elevation myocardial infarction-executive summary: a report of the American College of Cardiology/American Heart Association Task Force on Practice Guidelines (Writing Committee to Revise the 1999 Guidelines for the Management of Patients With Acute Myocardial Infarction). Circulation. 2004;110(5):588-636.

8. McNamara RL, Herrin J, Bradley EH, Portnay EL, Curtis JP, Wang Y, Magid DJ, et al. Hospital improvement in time to reperfusion in patients with acute myocardial infarction, 1999 to 2002. J Am Coll Cardiol. 2006;47(1):4551.

9. Bradley EH, Herrin J, Wang Y, Barton BA, Webster TR, Mattera JA, Roumanis SA, et al. Strategies for reducing the door-to-balloon time in acute myocardial infarction. 
N Engl J Med. 2006;355(22):2308-2320.

10. Canto JG, Rogers WJ, Bowlby LJ, French WJ, Pearce DJ, Weaver WD. The prehospital electrocardiogram in acute myocardial infarction: is its full potential being realized? National Registry of Myocardial Infarction 2 Investigators. J Am Coll Cardiol. 1997;29(3):498-505.

11. Magid DJ, Wang Y, Herrin J, McNamara RL, Bradley EH, Curtis JP, Pollack CV, Jr., et al. Relationship between time of day, day of week, timeliness of reperfusion, and inhospital mortality for patients with acute ST-segment elevation myocardial infarction. JAMA. 2005;294(7):803812.

12. Assali AR, Brosh D, Vaknin-Assa H, Fuchs S, Teplitsky I, Sela O, Kornowski R. The impact of circadian variation on outcomes in emergency acute anterior myocardial infarction percutaneous coronary intervention. Catheter Cardiovasc Interv. 2006;67(2):221-226.

13. Saleem MA, Kannam H, Aronow WS, Weiss MB, Kalapatapu K, Pucillo AL, Monsen CE. The effects of offnormal hours, age, and gender for coronary angioplasty on hospital mortality in patients undergoing coronary angioplasty for acute myocardial infarction. Am J Cardiol. 2004;93(6):763-764.

14. Dominguez-Rodriguez A, Garcia-Gonzalez M, AbreuGonzalez P. Outcome of primary angioplasty for ST-segment elevation myocardial infarction during routine duty hours versus during off-hours. Results of a single-center in Spain. Int J Cardiol. 2007;119(2):227-229.

15. Glaser R, Naidu SS, Selzer F, Jacobs AK, Laskey WK, Srinivas VS, Slater JN, et al. Factors associated with poorer prognosis for patients undergoing primary percutaneous coronary intervention during off-hours: biology or systems failure? JACC Cardiovasc Interv. 2008;1(6):681-
688.

16. Zahn R, Schiele R, Seidl K, Schuster S, Hauptmann KE, Voigtlander T, Gottwik M, et al. Daytime and nighttime differences in patterns of performance of primary angioplasty in the treatment of patients with acute myocardial infarction. Maximal Individual Therapy in Acute Myocardial Infarction (MITRA) Study Group. Am Heart J. 1999;138(6 Pt 1):1111-1117.

17. Sadeghi HM, Grines CL, Chandra HR, Mehran R, Fahy M, Cox DA, Garcia E, et al. Magnitude and impact of treatment delays on weeknights and weekends in patients undergoing primary angioplasty for acute myocardial infarction (the cadillac trial). Am J Cardiol. 2004;94(5):637640, A639.

18. Ortolani P, Marzocchi A, Marrozzini C, Palmerini T, Saia F, Aquilina M, Baldazzi F, et al. Clinical comparison of "normal-hours" vs "off-hours" percutaneous coronary interventions for ST-elevation myocardial infarction. Am Heart J. 2007;154(2):366-372.

19. Canto JG, Every NR, Magid DJ, Rogers WJ, Malmgren JA, Frederick PD, French WJ, et al. The volume of primary angioplasty procedures and survival after acute myocardial infarction. National Registry of Myocardial Infarction 2 Investigators. N Engl J Med. 2000;342(21):15731580.

20. Smith SC, Jr., Feldman TE, Hirshfeld JW, Jr., Jacobs AK, Kern MJ, King SB, 3rd, Morrison DA, et al. ACC/AHA/ SCAI 2005 guideline update for percutaneous coronary intervention: a report of the American College of Cardiology/American Heart Association Task Force on Practice Guidelines (ACC/AHA/SCAI Writing Committee to Update the 2001 Guidelines for Percutaneous Coronary Intervention). J Am Coll Cardiol. 2006;47(1):e1-121. 